effectiveness in the pedagogical monitoring organization in sports aerobics // Proceedings of the IX International Academic Congress "Contemporary Science and Education in Americas, Africa and Eurasia" (Brazil, Rio de Janeiro, 18-20 August 2015). Volume III. "UFRJ Press", 2015. - 522-530 p. [In Engl.].

12. Nazarenko L.D., Kasatkina N.A. Concept of movements virtuosity formation in highly-qualified athletes training. Teoriya I praktika fizicheskoj kul'ruty = Theory and practice of physical culture. 2016; 5: 7275 [In Russ., In Engl.].

13. Pakhomova L.E., Klimova M.V. Organization and methodology of physical training among children, who go in for variety-theatrical dancing. Teoriya I praktika fizicheskoj kul'ruty I sporta $=$ Theory and practice of physical culture and sports. 2009; 1: 34-40 [In Russ., In Engl.].
14. Tarkhanov I.V., Lukunina E.A., Shalmanov A.A. Biomechanics of interaction with the support during dancing steps backwards fulfillment in different tempo. Teoriya I praktika fizicheskoj kul'ruty I sporta $=$ Theory and practice of physical culture and sports. 2011; 5: 50-55 [In Russ., In Engl.].

15. Kuznetsova Z., Kuznetsov A., Mutaeva I., Khalikov G., Zakharova A., 2015. Athletes training based on a complex assessment of functional state. In Proceedings of the $3^{\text {rd }}$ International Congress on Sport Sciences Research and Technology support. SCITEPRESS. P. 156-160 (Scopus).

16. Kuznetsov A., Mutaeva I., Kuznetsova Z., 2017. Diagnostics of Functional State and Reserve Capacity of young Athletes' Organism. In Proceedings of the $5^{\text {th }}$ International Congress on Sport Sciences Research and Technology support. SCITEPRESS. P. 111-115 (Scopus).

\title{
Подано: 24.07.2018
}

Мингалишева Ирина Александровна - аспирант, Федеральное государственное бюджетное образовательное учреждение высшего образования «Ульяновский государственный педагогический университет имени И.Н. Ульянова», Россия, 432700 г. Ульяновск, Площчадь 100-летия со дня рождения В.И. Ленина, дом 4, e-тail: revinaira@yandex.ru

\section{СОВЕРШЕНСТВОВАНИЕ МОТИВАЦИОННОЙ СФЕРЫ И ПАМЯТИ КАК СТРУКТУРНЫХ КОМПОНЕНТОВ АФФЕРЕНТНОГО СИНТЕЗА ДВИГАТЕЛЬНЫХ НАВЫКОВ БОКСЕРА}

\author{
Осипов Д. A. $^{1}$ \\ ${ }^{1}$ ФГБОУ ВО «Ульяновский государственный педагогический университет имени И.Н. \\ Ульянова», Россия, г. Ульяновск, \\ Dima7692@yandex.ru
}

Аннотация. Качественное выполнение технических приемов в боксе имеют системный характер, что обусловлено согласованностью в деятельности двигательных $u$ вегетативных функиий. Такой значимый элемент нервной системы как афферентный (или анализаторный) компонент участвует в афферентном синтезе моторных актов, который, как установил академик П.К. Анохин, 1980, осуществляется при взаимодействии мотивачии, двигательной памяти, обстановочной и пусковой информации. Это детерминирует необходимость выявления роли мотиваџии и двигательной памяти в спортивных достижениях боксера. Материалы. $B$ данной статье представлено 
теоретическое обоснование значимости управления мотивами выбора бокса для занятий спортом, их влияние на отношение единобориа к тренировочному процессу. В боксе как высоко динамичном виде спорта возникают ситуачии, требующие мгновенного использования навыков ориентировки в пространственно-временных и пространственносиловых параметрах двигательных действий, решения сложных моторных задач в условиях ведения боя. Это предъявляет особые требования к двигательной памяти как одному из ведущих компонентов афферентного синтеза. Методы исследования: анализ $u$ систематизачия научно-методической литературы; обобщение передового педагогического опыта спечиалистов, тренеров по боксу, квалифицированных спортсменов; педагогический эксперимент, тестирование, методы математической статистики. Результаты. Автором разработана методика формирования мотивационной сферы квалифицированных боксеров; критерии оценки ее уровня. Большое внимание уделяется проблеме развития двигательной памяти как значимого фактора, способствующего накоплению личностного опьтта соревновательной деятельности; формированию навыка сопоставительного анализа стиля ведения спортивного поединка и противника; выявления и оценки сильных и слабых сторон своей индивидуальной техники. Заключение. Результатьл педагогического эксперимента показали эффективность разработанной методики управления мотивачионной сферой квалифицированных боксеров и развития двигательной памяти. Успешность соревновательной деятельности боксеров в значительной мере обусловлена не только положительной динамикой показателей физической и технико-тактической подготовленности, но и совершенствованием мотивационной сферь и уровнем развития двигательной памяти. Мотивачия, направленная на преобразование личностно ориентированных мотивов в сочиально значимые, а также двигательная память являются важными элементами не только афферентного синтеза двигательных действий, но и системы спортивной подготовки боксеров.

Ключевые слова: бокс, афферентный синтез, мотивация, двигательная память, педагогический эксперимент, критерии оценки.

Для цитирования: Осипов Д.А. Совершенствование мотивационной сферы и памяти как структурных компонентов афферентного синтеза двигательных навыков боксера. Педагогико-психологические и медико-биологические проблемы физической культуры и cnopma. 2018; 13(3): 57-65. DOI 10.14526/2070-4798-2018-13-3-57-65.

\title{
MOTIVATIONAL SPHERE AND MEMORY IMPROVEMENT AS STRUCTURAL COMPONENTS OF BOXER'S MOTOR SKILLS AFFERENT SYNTHESIS
}

\author{
Osipov D. A. ${ }^{1}$ \\ ${ }^{1}$ Federal State Budgetary Educational Establishment of Higher Education \\ “Ulyanovsk State Pedagogical University Named After I.N. Ulyanov”, Russia, Ulyanovsk, \\ Dima7692@yandex.ru
}

Annotation. Qualitative fulfillment of techniques in boxing has systematic character, which is
conditioned by consistency in motor activity and vegetative functions. Such an important element
of nervous system, as afferent (or analyzer) component, takes part in afferent synthesis of motor
acts, which is realized during interaction between motivation, motor memory, setting and start-up
information, as it was set by academic P.K. Anokhin, 1980. It determines the necessity to reveal the
role of motivation and motor memory in a boxer's sports achievements. Materials. The article
presents theoretical importance substantiation of boxing choosing motives control for sports
lessons, their influence on combatant's attitude to training process. Boxing is a highly dynamic kind
of sport, that is why appearing situations in it demand quick use of orientation skills in spatio-
temporal and spatio-power parameters of motor actions, difficult motor objectives solution in terms 
of combat. This is the reason why motor memory should be developed, as one of afferent synthesis leading components. Research methods: scientific-methodical literature analysis and systematization; summarizing progressive pedagogical experience of the specialists, boxing trainers, qualified athletes; pedagogical experiment, testing, methods of mathematical statistics. Results. The author created the methodology of motivational sphere formation among qualified boxers; evaluation criteria of its level. Great attention is paid to the problem of motor memory development as an important factor, which provides personal experience of competitive activity accumulation; the skill of comparative analysis formation, concerning the style of sports combat and the opponent; strong and weak points of own individual technique revelation and estimation. Conclusion. The results of the pedagogical experiment showed the effectiveness of the created motivational sphere management methodology and motor memory development among qualified boxers. The success of boxers' competitive activity is mainly conditioned not only by positive dynamics of physical and technical-tactical readiness indices, but also by motivational sphere improvement and motor memory level. Motivation, directed at personality-oriented motives transformation into socially important ones and also motor memory are important elements not only of motor actions afferent synthesis, but also of boxers' sports training system in general.

Keywords: boxing, afferent synthesis, motivation, motor memory, pedagogical experiment, evaluation criteria.

For citations: Osipov D.A. Motivational sphere and memory improvement as structural components of boxer's motor skills afferent synthesis. The Russian Journal of Physical Education and Sport (Pedagogico-Phycological and Medico-Biological Problems of Physical Culture and Sports). 2018; 13(3): 57-65. DOI 10.14526/2070-4798-2018-13-3-57-65.

\section{ВВЕДЕНИЕ}

Бокс является общедоступным видом спортивной деятельности, в котором основные требования предъявляются к быстроте двигательной реакции, скорости переключения внимания; устойчивости тела, сохранению хладнокровия и выдержки в стрессовых ситуациях поединка. Как полагает И.С. Колесник, 2010, 2017, 2018, главной особенностью бокса является стремление единоборцев к нанесению прицельного, мощного удара в болевую точку. Это требует большого мужества, терпения, самообладания, постоянного повышения уровня общефизической и техникотактической подготовленности. Проявление и совершенствование данных качеств обусловлено генетической предрасположенностью к рассматриваемому виду спорта, характеризующемуся быстрой сменой неожиданно возникающих ситуаций, непредсказуемостью действий противника, своевременным изменением нервномышечного напряжения $[11,12,16]$.
При построении тренировочного процесса большое значение имеет выявление мотивов выбора бокса как вида спорта, наиболее отвечающего внутренним, не всегда осознанным возможностям и потребностям организма. В боксе, связанном с большим риском получения травмы различной тяжести, большую роль выполняет двигательная память, позволяющая накапливать индивидуальный опыт ведения боксерского поединка; выявлять знакомые ситуации, требующие принятия адекватного решения, от скорости и эффективности которого зависит исход встречи с соперником.

Целью данной работы является теоретическое обоснование необходимости совершенствования роли мотивационной сферы и памяти компонентов афферентного синтеза двигательного навыка для повышения уровня технической подготовленности квалифицированных боксеров.

Задачи: 1. Установить значение мотивации и памяти - ведущих компонентов афферентного синтеза для 
усвоения техники сложных двигательных действий, составляющих индивидуальный стиль деятельности единоборца.

2. Разработать методику совершенствования мотивационной сферы и двигательной памяти - структурных компонентов афферентного синтеза, с последующей еe экспериментальной проверкой.

\section{МАТЕРИАЛЫ И МЕТОДЫ}

Квалифицированному боксеру присуща экономичность двигательных и защитных приемов. При выборе способа выполнения ударного действия спортсмен руководствуется определенным мотивом. Так, для достижения быстрой эффектной победы, самоутверждения, реализации определенных целей и задач спортивной подготовки единоборец предпочитает агрессивный вид ведения спортивного поединка; его целью является нанесение точных, мощных ударов в незащищенные зоны соперника. Боксеры с интеллектуальной манерой ведения боя стремятся переиграть противника путем применения неожиданного приема, требующего высокой степени координации разнохарактерных двигательных действий, резкости, ловкости, быстроты двигательных реакций, объективной оценки сложившейся ситуации [3 - 5, 7, 8, 15].

Психологическая установка на силовую манеру ведения поединка в значительной мере определяет содержание программы спортивной подготовки боксера; выбор соответствующих упражнений, направленных на развитие скоростно-силовых качеств; формирование навыков проведения неожиданных мощных ударов; совершенствование разнообразных защитных приемов, позволяющих своевременно уходить от атакующих действий соперника. Универсальный вид спортивной подготовки боксера ориентирован на его разностороннее развитие с учетом типологических и генетических особенностей; мотивационной сферы; уровня сформированности двигательной памяти, позволяющей запоминать особенности ведения поединка боксерами с разными индивидуальными параметрами. С развитием двигательной памяти существенно расширяются возможности успешного решения сложной задачи в неожиданно возникающих условиях; поиска наиболее эффективного выхода из ситуаций, определяющих исход боксерского поединка. В процессе взаимодействия с сильным, опытным противником благодаря следовым явлениям формируются прочные временные связи, позволяющие устанавливать зависимость между исходным положением боксера, его подготовительными действиями и последующими атакующими приемами, сила воздействия которых определяется степенью готовности единоборца к их отражению $[6,8,10,14]$.

Кратковременная и долговременная память решают свои конкретные задачи в технико-тактической подготовке единоборца. Благодаря кратковременной памяти спортсмен контролирует действия соперника, которые характеризуют особенности ведения поединка, обусловленные уровнем квалификации, сформированностью индивидуального стиля ведения боя. Показатели кратковременной памяти позволяют осуществлять контроль изменений скорости движений, последовательностью серийных и одиночных ударов; выполнением обманных движений, сменой темпо-ритмовых параметров движений, что дает возможность владеть ситуацией и прогнозировать действия противника.

\section{Долговременная}

память обеспечивает сохранение способов проведения технически сложных приемов в конкретных ситуациях, выполняемых противником без предварительной подготовки, с непредсказуемыми последствиями. Это обеспечивает накопление личного опыта противоборства с соперником, обусловливающего необходимость контроля, оценки и прогнозирования каждого действия; 
повышение психологической готовности к многовариативному поведению; удержанию в поле зрения двигательных действий соперника, распределению внимания на элементы маневрирования как одного из видов подготовки к выбору атакующего приема. В связи с этим для совершенствования технико-тактической подготовки квалифицированного боксера необходимо предусматривать разработку специальной программы индивидуального формирования навыков управления мотивационной сферой спортсмена, a также развития памяти как значимых компонентов афферентного синтеза $[1,13]$.

РЕЗУЛЬТАТЫ

ИССЛЕДОВАНИЯ

И ИX ОБСУЖДЕНИЕ

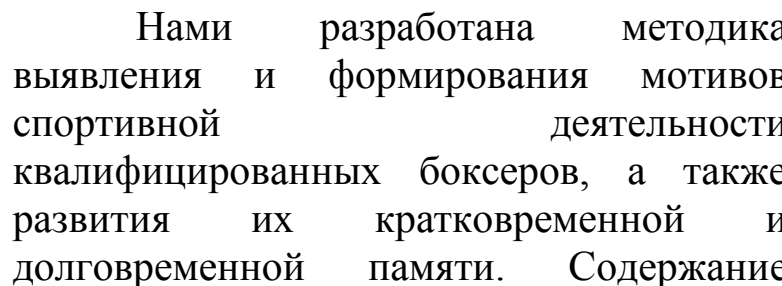
методики предусматривает проведение специальных бесед, устных и письменных опросов с целью выявления мотивов выбора бокса для спортивного совершенствования. Анализ научной и научно-методической литературы, материалы наших собственных исследований показали, что на этапе начальной спортивной подготовки у спортсменов преобладают личностноориентированные мотивы: стать сильным и ловким; для самоутверждения; с целью самозащиты и др. По мере роста спортивного мастерства, приобретения опыта соревновательной деятельности происходит закономерное совершенствование мотивационной сферы и на первый план выходят мотивы другой направленности: научиться противостоять сильному, многоопытному противнику; выявить свои возможности и способности в интеллектуальной, общефизической, технико-тактической подготовленности; попасть в составе сборной команды на крупнейшие международные соревнования и др.
Для формирования мотивационной
сферы использовались
методические предусматривающие разностороннее изучение личности спортсмена; выявляльсь фенотипологические особенности, латентные возможности и способности, личностные свойства, степень умственной и физической работоспособности, предрасположенность к самосовершенствованию, готовность к самодисциплине, самоограничениям как базису спортивного стиля жизни; определялся волевой потенциал боксера, уровень его духовно-нравственного развития. Это позволяло формировать психологические установки на достижение спортивных результатов в соответствии с этапами спортивной подготовки, ее целями и задачами, динамикой соревновательных результатов. Постановка постепенно усложняющихся целей и задач, выбор эффективных индивидуальных средств и методов их реализации обеспечивали последовательный рост спортивных результатов; расширение системы специальных знаний. Развитие способностей к общению с ведущими спортсменами позволяло изучать индивидуальный опыт спортивной подготовки сильнейших единоборцев, что оказывало существенное воздействие на мотивационную сферу спортсмена; способствовало преобразованию его личностно ориентированных мотивов в социально значимые $[9,17]$.

Методика развития двигательной памяти предусматривала разработку двигательных заданий, направленных на установление и запоминание взаимосвязей между системой подготовительных, подводящих и основных физических упражнений; особенностей боевой стойки боксера в конкретной ситуации с последующим выполнением двигательных действий; между способами выполнения маневрирования и выбором приема проведения ударного действия. Большое внимание уделялось выявлению взаимозависимости атакующих и 
защитных приемов, их количеством, чередованием; определению моментов ускорения двигательных действий, изменения их темпо-ритмовых параметров; выявлению особенностей подготовительных действий перед истинным и ложным атакующим приемом; выбору соревновательной дистанции, способа передвижения и вида ударного действия и т.д.

\begin{tabular}{|c|c|c|}
\hline \multicolumn{2}{|c|}{ Значимость } & формирования \\
\hline двигательной & памяти & обусловлена \\
\hline существенным & & расширением \\
\hline
\end{tabular}
возможностей боксера по установлению контроля действий соперника. Это позволяет моделировать собственные действия на ринге в процессе соревновательной деятельности с учетом специфики возникающей ситуации. Благодаря двигательной памяти квалифицированный боксер устанавливает отличия в тактике ведения боя спортсменами с различным уровнем технико-тактической подготовленности, опытом соревновательной деятельности, различными манерами ведения поединка, другими индивидуальными особенностями.

Для развития кратковременной двигательной памяти боксерам предлагались следующие задания:

- воспроизведение количества серийных ударных действий противника непосредственно после окончания поединка;

установление количества защитных действий, применяемых при проведении серий и отдельных атакующих ударов;

- выявление используемых способов передвижения и частоты их смены в каждом раунде поединка;

- определение предпочтительных и редко используемых дистанций, оценка целесообразности их использования в каждой возникающей ситуации;

- установление индивидуальных особенностей маневрирования перед атакующим приемом;
- выявление успешных и неудачных атакующих приемов, причин их неэффективности.

Подобные задания предлагались единоборцам на следующий день после участия на соревнованиях; спустя неделю, затем через месяц.

Долговременная двигательная память формировалась с установкой на необходимость

запоминания

индивидуальных особенностей ведения поединка боксера с каждым противником в течение года, оценки достижений противника, его положительного опыта, достойного осмысления и творческой интерпретации с п последующим использованием в собственной системе спортивной подготовки.

С целью проверки эффективности методики формирования мотивационной сферы и развития двигательной памяти был проведен педагогический эксперимент, в котором приняли участие квалифицированные боксеры 14-15 лет. В педагогическом эксперименте было задействовано 39 спортсменов II и I разрядов. Были организованы контрольная группа (КГ) - 19 человек, и экспериментальная группа (ЭГ) - 20 человек. В КГ тренировочные занятия проводились по общепринятой методике в соответствии с программой спортивной подготовки квалифицированных боксеров, утвержденной федерацией бокса РФ [2].

Перед началом педагогического эксперимента группой высококвалифицированных тренеров по боксу были выявлены исходные показатели сформированности мотивов спортивной деятельности и развития двигательной памяти у спортсменов КГ и ЭГ. Состояние мотивационной сферь оценивалось по выбору и обоснованию конкретных мотивов, умению их сформировать и распределить по степени значимости.

Критерии оценки (в баллах):

5 баллов - хочу узнать, на что я способен, испытать свой характер, стать настоящим спортсменом; 
4 балла - научиться боксировать, как лучшие спортсмены; никого не бояться, уметь постоять за себя;

3 балла - тренер пригласил заниматься боксом; в классе несколько человек тренируются в секции бокса, я тоже решил попробовать;

2 балла - хороший тренер; может быть, стану сильным боксером;

1 балл - бокс интереснее других видов спорта.

Уровень развития двигательной памяти определялся по следующим показателям: точное воспроизведение отличительных признаков ведения боя противником, их объективная оценка; логическое построение ответа по характеристике уровня техникотактической подготовки соперника; способность выявлять детали, подчеркивающие индивидуальный стиль ведения боя противником.

Критерии очзенки (в баллах):

5 баллов - последовательное изложение особенностей поведения противника на ринге; умение выделить главное, подчеркнуть недостатки;

4 балла - умение обосновать признаки сформированности индивидуального стиля боя, отметить изменения в поведении соперника по отдельным раундам;

3 балла - верное перечисление видов атакующих и защитных приемов, особенностей их проведения; недооценка применения различных дистанций и способов передвижения;

2 балла - неумение перечислить удары, составляющие серию, назвать все защитные действия;

1 балл - перечислены несколько одиночных атакующих приемов.

Анализ результатов исследования не выявил существенных различий $\mathrm{y}$ боксеров КГ и ЭГ по уровню сформированности мотивационной сферы и по развитию двигательной памяти $(\mathrm{p}>0,05)$.

После окончания педагогического эксперимента была проведена повторная оценка показателей проявления мотивов выбора бокса для занятий спортом и развития двигательной памяти с использованием тех же критериев оценки. Полученные данные показали, что улучшение показателей произошло в обеих группах: КГ и ЭГ, при явном преимуществе спортсменов ЭГ. Так, в КГ при исходных данных уровня сформированности мотиваџионной сферы $2,69 \pm 0,18$ балла к окончанию педагогического эксперимента показатели улучшились до 2,77 $\pm 0,21$ балла, (p>0,05); в ЭГ, соответственно, при исходных данных $2,76 \pm 0,15$ балла к завершению педагогического эксперимента результаты возросли до $3,41 \pm 0,24$ балла, $(\mathrm{p}<0,05)$. В КГ при исходных данных развития двигательной памяти 2,79 $\pm 0,20$ балла к окончанию педагогического эксперимента показатели улучшились до $2,86 \pm 0,17$ балла, $(\mathrm{p}>0,05)$; в ЭГ, соответственно, при исходных данных 2,81 $\pm 0,23$ балла к завершению педагогического эксперимента результаты возросли до $3,67 \pm 0,22$ балла, $(\mathrm{p}<0,05)$.

\section{ЗАКЛЮЧЕНИЕ}

Таким образом, результаты педагогического эксперимента показали, что спортивная подготовка боксеров является сложным, многопараметрическим процессом, эффективность которого обусловлена многими факторами, среди которых важное место занимает управление формированием мотивационной сферы, а также развитием двигательной памяти. Качественное изменение мотивов выбора бокса для занятий спортом позволяет ставить перед боксером более сложные цели и задачи, оказывать существенное воздействие на формирование его личностных свойств. Целенаправленное развитие двигательной памяти способствует формированию личностного соревновательного опыта единоборца; навыков анализа и оценки собственного уровня технико-тактической подготовки, критического переосмысления индивидуальной программы на предстоящий этап спортивной подготовки, 
что стимулирует его двигательную активность. Результаты проведенного педагогического эксперимента показали значимость использования методики формирования мотивационной сферы и совершенствования двигательной памяти боксеров.

\section{Список литературы}

1. Анохин П.К. Очерки по физиологии функциональных систем. М.: Медицина. 1975: 447.

2. Акопян А.О. Бокс: Примерная программа спортивной подготовки для детскоюнотеских спортивных школ, специализированных детско-юношеских школ олимпийского резерва. М.: Советский спорт. 2007: 72.

3. Дикунов А.М., Бурачук М.Ю. Самовоспитание спортсменов. Теория и практика физической культуры. 1984; 4: 20-21.

4. Колесник И.С. Актуализация проблемы формирования личности в процессе занятий боксом. Теория и практика физической культуры. 2007; 5: 46-48.

5. Колесник И.С. Личность боксера. М.: Научно-издательский центр «Теория и практика физической культуры и спорта». 2008: 159.

6. Колесник И.С. Структура и содержание спортивной подготовки боксеров 15-17 лет. Ульяновск. 2010: 342.

7. Колесник И.С. Основные направления повышения эффективности системы спортивной подготовки квалифищированных боксеров. М.: Флинта: наука. 2010: 350.

8. Колесник И.С., Гатин Ф.А., Алекседров Ю.М. Роль прочности двигательного навыка в системе спортивной подготовки квалифицированных боксеров. Педагогикопсихологические и медико-биологические проблемы физической культуры и спорта. 2015; 4 4-37(37): 111-119. URL: $\quad$ http://www.journalscience.org/ru/article/268.html. DOI $\underline{10.14526 / 01 \_111158}$.

9. Колесник И.С., Гатин Ф.А., Осипов Д.А. Формирование коммуникативных навыков в процессе спортивной подготовки боксеров. Педагогико-психологические и медикобиологические проблемь физической культуры и cnopma. 2016; 1: 40-46. URL: http://www.journalscience.org/ru/article/306.html. DOI 10.14526/01_1111_77.

10. Котешев В.Е. Использование технических средств контроля за уровнем специальной подготовленности боксеров. Материаль научной и научно-методической конференции профессорско-преподавательского состава Кубанского государственного университета физической культуры, спорта и туризма. 2015; 2: 24-25.
11. Кузнецова 3.М., Зайнуллин Ш.Р. Анализ особенностей подготовки к соревновательной деятельности боксеров-новичков 15-18 лет. Вестник спортивной науки. 2007; 3: 2729.

12. Лукьяненко В.П., Воликов Р.А. Оптимизация тренировочного процесса в ударных видах спортивных единоборств на предсоревновательном этапе (на примере бокса и кикбоксинга). Вестник Северо-Кавказского федерального университета. 2016; 4(55): 196-199.

13. Nazarenko L.D., Kolesnik I.S. Physiological bases of improvement system of boxers sports training. Life Science Journal. 2014; 11(11s): 642-645. URL: http://www.lifesciencesite.com.

14. Назаренко Л.Д., Колесник И.С., Осипов Д.А. Физиологические основы совершенствования системы спортивной подготовки боксеров. Педагогико-психологические и медикобиологические проблемы физической культуры и спорта. 2017; 12(4): 169-177. URL: http://www.journal-science.org/ru/article/927.html. DOI 10/14526/ 042017277.

15. Назаренко Л.Д. Физиология физических упражнений. Ульяновск: ФГБОУ ВО «УлГПУ им. И.Н. Ульянова». 2017: 262.

16. Осипов Д.А., Колесник И.С. Факторы, влияющие на уровень спортивной подготовленности боксеров массовых разрядов 1314 лет. Физическая культура: воспитание, образование, тренировка. 2017; 1: 34-38

17. Kuznetsova Z., Kuznetsov A., Mutaeva I., Khalikov G., Zakharova A., 2015. Athletes training based on a complex assessment of functional state. In Proceedings of the $3^{\text {rd }}$ International Congress on Sport Sciences Research and Technology support. SCITEPRESS. P. 156-160 (Scopus).

18. Kuznetsov A., Mutaeva I., Kuznetsova Z., 2017. Diagnostics of Functional State and Reserve Capacity of young Athletes' Organism. In Proceedings of the $5^{\text {th }}$ International Congress on Sport Sciences Research and Technology support. SCITEPRESS. P. 111-115 (Scopus).

\section{References}

1. Anokhin P.K. Ocherki po fiziologii funkcional'nyh sistem [An outline of functional systems physiology]. Moscow: Medicine. 1975: 447.

2. Akopyan A.O. Boks: Primernaya programma sportivnoj podgotovki dlya detskoyunosheskih sportivnyh shkol, specializirovannyh detsko-yunosheskih shkol olimpijskogo rezerva [Boxing: Model program of sports training for sports schools for children and teen-agers, specialized schools of the Olympic reserve for children and teen-agers]. Moscow: Soviet sport. 2007: 72.

3. Dikunov A.M., Burachuk M.Yu. Selfupbringing of sportsmen. Teoriya I praktika fizicheskoj kul'tury = Theory and practice of physical culture. 1984; 4: 20-21 [In Russ., In Engl.]. 
4. Kolesnik I.S. The problem of personality formation actualization during boxing lessons. Teoriya I praktika fizicheskoj kul'tury $=$ Theory and practice of physical culture. 2007; 5: 46-48 [In Russ., In Engl.].

5. Kolesnik I.S. Lichnost' boksera [A boxer's personality]. Moscow: Scientific-publishing center "Theory and practice of physical culture and sport". 2008: 159.

6. Kolesnik I.S. Struktura I soderzhanie sportivnoj podgotovki bokserov 15 - 17 let [Structure and content of sports training among 15-17-year-old boxers]. Ulyanovsk. 2010: 342.

7. Kolesnik I.S. Osnovnye napravleniya povysheniya effektivnosti sistemy sportivnoj podgotovki kvalificirovannyh bokserov [The main directions of sports training system effectiveness increase among qualified boxers]. Moscow: Flinta. 2010: 350.

8. Kolesnik I.S., Gatin F.A., Aleksandrov Yu.M. The role of motor skill strength in the system of qualified boxers sports training. Pedagogikopsihologicheskie I mediko-biologicheskie problemy fizicheskoj kul'tury I sporta = Pedagogicopsychological and medico-biological problems of physical culture and sport. 2015; 4 4-37(37): 111-119. URL: http://www.journalscience.org/ru/article/268.html. DOI 10.14526/01_1111_58 [In Russ., In Engl.].

9. Kolesnik I.S., Gatin F.A., Osipov D.A. Communicative skills formation during sports training of boxers. Pedagogiko-psihologicheskie I medikobiologicheskie problemy fizicheskoj kul'tury I sporta = Pedagogico-psychological and medico-biological problems of physical culture and sport. 2016; 1: 40-46. URL: http://www.journalscience.org/ru/article/306.html. DOI 10.14526/01_1111_77 [In Russ., In Engl.].

10. Koteshev V.E. Technical means of control use over boxers' special readiness level. Materialy nauchnoj I nauchno-metodicheskoj konferencii professorsko-prepodavatel'skogo sostava Kubanskogo gosudarstvennogo universiteta fizicheskoj kul'tury, sporta I turizma [Materials of scientific and scientificmethodical conference of teaching staff of Kuban State University of Physical Culture, Sport and Tourism]. 2015; 2: 24-25.

11. Kuznetsova Z.M., Zaynullin Sh.R. The peculiarities analysis of training for competitive activity among 15-18-year-old boxers-beginners. Vestnik sportivnoj nauki = Sports science bulletin . 2007; 3: 27-29 [In Russ., In Engl.].

12. Lukyanenko V.P., Volikov R.A. Training process optimization in striking kinds of combats at pre-competitive stage (by the example of boxing and kick-boxing). Vestnik Severo-Kavkazskogo federal'nogo universiteta. 2016; 4(55): 196-199 [In Russ.].

13. Nazarenko L.D., Kolesnik I.S. Physiological bases of boxers sports training system improvement. Life Science Journal. 2014; 11(11s): 642-645. URL: http://www.lifesciencesite.com [In Engl.].

14. Nazarenko L.D., Kolesnik I.S., Osipov D.A. Physiological bases of boxers sports training system improvement. Pedagogiko-psihologicheskie I mediko-biologicheskie problemy fizicheskoj kul'tury I sporta = Pedagogico-psychological and medicobiological problems of physical culture and sport. 2017; 12(4): 169-177. URL: http://www.journalscience.org/ru/article/927.html. DOI 10/14526/ 04 2017277 [In Russ., In Engl.].

15. Nazarenko L.D. Fiziologiya fizicheskih uprazhnenij [Physical exercises physiology]. Ulyanovsk: Federal State Budgetary Educational Establishment of Higher Education "Ulyanovsk State Pedagogical University Named After I.N. Ulyanov. 2017: 262 .

16. Osipov D.A., Kolesnik I.S. Factors, which influence sports readiness level of 13-14-year-old boxers of mass categories. Fizicheskaya kul'tura: vospitanie, obrazovanie, trenirovka. 2017; 1: 34-38 [In Russ.].

17. Kuznetsova Z., Kuznetsov A., Mutaeva I., Khalikov G., Zakharova A., 2015. Athletes training based on a complex assessment of functional state. In Proceedings of the $3^{\text {rd }}$ International Congress on Sport Sciences Research and Technology support. SCITEPRESS. P. 156-160 (Scopus).

18. Kuznetsov A., Mutaeva I., Kuznetsova Z., 2017. Diagnostics of Functional State and Reserve Capacity of young Athletes' Organism. In Proceedings of the $5^{\text {th }}$ International Congress on Sport Sciences Research and Technology support. SCITEPRESS. P. 111-115 (Scopus).

\section{Подано: 28.05.2018}

Осипов Дмитрий Андреевич - аспирант, Федеральное государственное бюджетное образовательное учреждение высшего образования «Ульяновский государственный педагогический университет имени И.Н. Ульянова», Россия,432700 г. Ульяновск, Площадь 100-летия со дня рождения B.И. Ленина, дом 4, e-mail: Dima7692@yandex.ru 